\title{
Tidally driven stick-slip motion in the mouth of Whillans Ice Stream, Antarctica
}

\author{
Robert A. BINDSGHADLER, ${ }^{1}$ Patriaia L. VORnBerger, ${ }^{2}$ Matt A. King,${ }^{3}$ Laurie PadMaN ${ }^{4}$ \\ ${ }^{1}$ NASA Goddard Space Flight Center, Code 971, Greenbelt, MD 20771, U.S.A. \\ E-mail: robert.a.bindschadler@nasa.gov \\ ${ }^{2}$ SAIC, Beltsville, MD 20705-2675, U.S.A. \\ ${ }^{3}$ Department of Geomatics, University of Newcastle, Newcastle upon Tyne NE1 7RU, England \\ ${ }^{4}$ Earth \& Space Research, 1910 Fairview Ave. E., Suite 102, Seattle,WA 98102-3620, U.S.A.
}

\begin{abstract}
We show that the ice plain in the mouth of Whillans Ice Stream (formerly Ice Stream B), Antarctica, moves by stick-slip motion. During a spring-tide period, rapid motions regularly occur near high tide and during falling tide. This correlation is weaker during a neap-tide period when the tidal magnitudes are less. Precise timing of these motion events suggests that they propagate through the region with a mean velocity of $88 \mathrm{~m} \mathrm{~s}^{-1}$. We hypothesize that this speed is associated with the propagation of shear waves through a wet subglacial till. Motion events are also seen on more smoothly flowing floating ice. Event delays are very short between grounded and floating stations, suggesting the events propagate through the ice shelf as an elastic wave. We further hypothesize the events are caused by the interaction of a sticky bed, the accumulation of stored elastic strain through the compression of ice by upstream inflow, and tidal forcing. Motion events seem to be triggered either by reduction of vertical normal stresses at high tide or by the increase of shear stresses from sub-shelf ocean currents during falling tide. Event magnitudes are not related to the length of the preceding quiescent period, suggesting significant viscous dissipation within the till.
\end{abstract}

\section{INTRODUGTION}

Whillans Ice Stream (formerly Ice Stream B), Antarctica (Fig. 1), is the most studied ice stream in the world, but continues to surprise researchers. Scientific investigations on this ice stream began in 1957, when its downstream portion was crossed during the International Geophysical Year, well before the existence of ice streams was recognized. This area was later included in the Ross Ice Shelf Geophysical and Glaciological Survey (RIGGS) during the 1970s, when this entire area was thought to be part of the floating Ross Ice Shelf. Since the discovery of ice streams, this ice stream has received intensive surface-based work, airborne surveys and satellite monitoring (see review by Whillans and others, 2001). Much of our current understanding of ice-stream mechanics results from these studies, including the discovery and sampling of the weak subglacial till that supports rapid icestream motion (Blankenship and others, 1987; Engelhardt and Kamb, 1998; Kamb, 2001) and the first recognition that ice-stream margins are the sites of major resistive forces determining ice-stream speed (Whillans and Van der Veen, 1997). Currently, this ice stream is decelerating (Bindschadler and Vornberger, 1998; Joughin and Tulaczyk, 2002), providing scientists with a magnificent natural experiment in icestream response behavior.

The mouth of Whillans Ice Stream contains a region called an "ice plain" (Fig. 1), where surface slopes are intermediate between those of active ice streams (order $10^{-2}$ ) and ice shelves (order $10^{-4}$ ), the ice thickness above buoyancy is only tens of meters, the basal shear stress is extremely low (order $1 \mathrm{kPa}$ ), and the bed is a till delta comprised of foresetted stratigraphy (Shabtaie and Bentley, 1987; Alley and others, 1989; Bindschadler, 1993). The heritage of field observations of the ice plain made it an obvious site to extend the measurements of deceleration and to examine their spatial variation, if any. A program designed to efficiently collect these data revealed the unexpected behavior of sudden, short-lived motions of the ice, interspersed with much longer periods of stagnation. This paper reports on this behavior and offers hypotheses to explain it.

Tides are known to affect the motion of tidewater glaciers (Meier and Post, 1987; Walters and Dunlap, 1987; O'Neel and others, 2001). The floating portions of these glaciers rise and fall with the tide, while their horizontal speeds decrease as the tide rises and increase as the tide falls. The opposite relationship between tides and horizontal motion was reported in Greenland on Jakobshavn Isbræ (O'Neel and others, 2001).

Tides also affect the vertical position of ice shelves, but it has only recently been reported that tides also affect the horizontal motion of both floating ice and adjacent grounded ice in Antarctica. Direct measurements have been made on Amery, Brunt and Ross Ice Shelves. Several sites on the Amery Ice Shelf exhibit unidirectional horizontal motion based on global positioning system (GPS) measurements (King and others, in press). However, GPS records from the Brunt Ice Shelf show that ice shelf experiences quasi-cyclonic horizontal motions that are related to the ocean tides or currents, with the maximum downstream velocity reached about 4 hours before high tide. These motions result in horizontal velocity reductions 


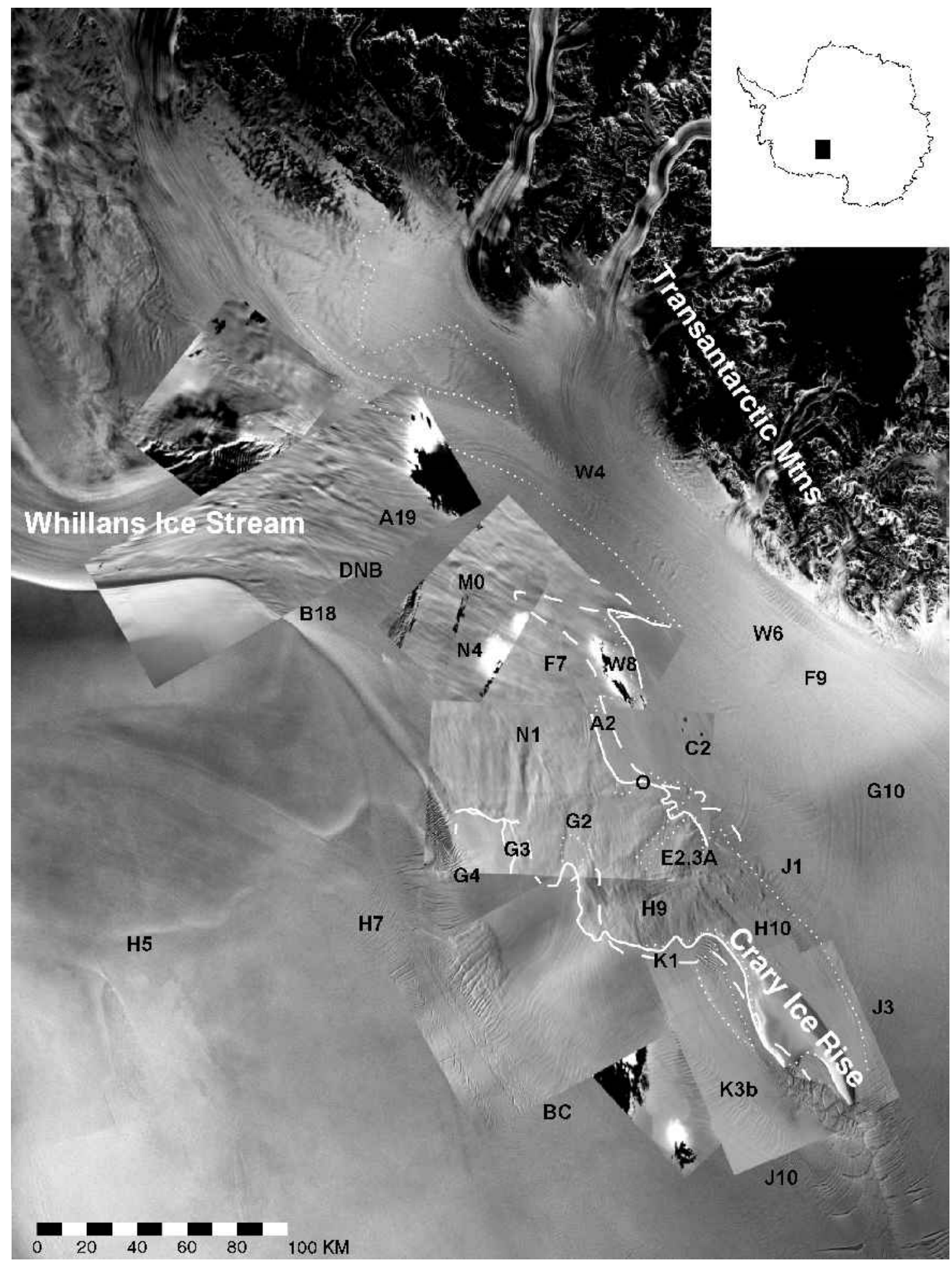

Fig. 1. Map of study area. Station names are centered on station locations. Lines of different types represent different interpretations of grounding line: solid, Bindschadler (1993); dashed, S. Shabtaie (unpublished information); dotted, Gray and others (2002). Grounded ice is recognized by the more undulated surface character in this composite of SPOT (smaller squares) and RADARSAT (background) imagery. The "ice plain" is the area of grounded ice downstream of the stations B18, DNB and A19 and upstream of Crary Ice Rise.

typically $50 \%$, and even $>100 \%$, of the long-term velocity (Doake and others, 2002). Where it enters the Ross Ice Shelf, Ice Stream D exhibits a $50 \%$ variation in the downstream speed in anti-phase with the tide (Anandakrishnanand others, 2003). This variation is diminished $40 \mathrm{~km}$ upstream and is not seen $80 \mathrm{~km}$ upstream, although the site of this final observation may be poorly chosen to detect residual tidal influence on ice motion.

Previous to these studies, variations in vertical strain and in basal water pressure at tidally synchronous periods were observed $300 \mathrm{~km}$ upstream of the grounding line on Whillans Ice Stream (Harrison and others, 1993; Engelhardt and Kamb, 1997) and in the seismicity of the lower $86 \mathrm{~km}$ of the nearly stagnant Ice Stream C (Anandakrishnan and Alley, 1997). In this latter study, a flow relationship was inferred that predicted higher flow rates at low tide (as later observed on Ice Stream D).

Our report describes the most extreme example of 


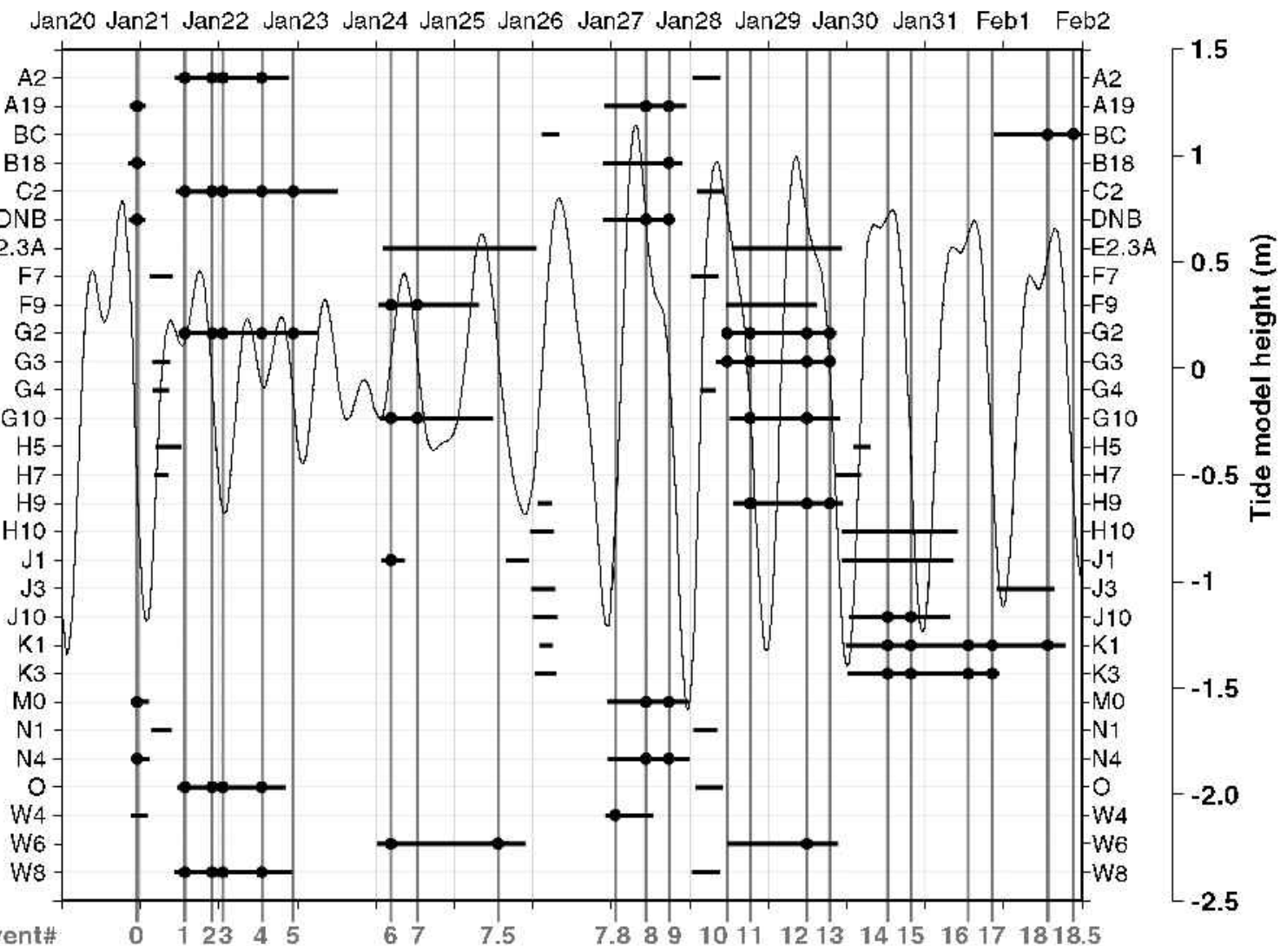

Fig. 2. Temporal plot of station occupations, motion events and composite tidal curve. Date of 1999 is indicated across the top. Each station is listed along the vertical. Thick horizontal lines indicate when a GPS receiver occupied a station. Solid circles denote the identification of a motion event from the GPS positions. Vertical lines connect events seen at multiple stations and are numbered across the bottom to allow discussion in the text. Thin oscillatory curve is a composite of predicted tidal magnitude discussed in text.

known tidal influence on horizontal ice motion. During most of the tidal cycle much of the ice plain is completely stationary, only moving forward during brief periods at high tide and at the midpoint of the falling tide. These short-period motion events are observed to propagate across the ice plain and onto the ice shelf.

\section{DATA}

The motion described in this paper was not anticipated. The data used were collected originally to better quantify the known multi-decadal deceleration of the Whillans Ice Stream ice plain (Bindschadler and Vornberger, 1998), and the collection strategy was designed for that purpose. To avoid the spatial interpolations and extrapolations necessary in previous velocity-change calculations, stations for the designed study were selected from sites occupied during either RIGGS, about 25 years earlier, or the Siple Coast Project (SCP), about 15 years earlier. Geodetic-quality Ashtech Z-12 GPS receivers were used with data stored internally and power supplied by deep-cycle marine batteries. Receivers were deployed by a one-man crew transported by Twin Otter using on-board GPS navigation to ensure accurate positioning of the receivers at former RIGGS and SCP sites. A minimum occupation time of 4 hours was imposed to determine an accurate site position. The minimum interval between surveys was set at 1 week. Based on the average velocity of the ice plain $\left(400 \mathrm{~m} \mathrm{a}^{-1}\right)$ and the anticipated $\pm 10 \mathrm{~cm}$ precision of the site coordinates, this plan ensured a velocity precision well under $1 \%$, meeting the goal of precise velocity measurements at many locations determined over a relatively short period of time in a single season.

Twenty-nine stations were occupied twice during January 1999 (Fig. 1). Occupation times varied widely depending on aircraft logistics. Often receivers were left overnight or, in cases of inclement weather, for multiple days with data collection continuing until the external battery drained. Multiple receivers were deployed during a given flight, usually in the same vicinity, to minimize flight times between stations. Subsequent flights picked up and redeployed receivers. Data were downloaded to laptop computers during redeployment flight legs, and batteries were recharged overnight at Siple Dome, the base used during the survey. Figure 2 shows the temporal record of station occupations.

We processed the GPS data using the Precise Point Positioning (PPP) technique as implemented in the GIPSY/OASIS software (Zumberge and others, 1997), estimating site coordinates and tropospheric zenith delay parameters every $5 \mathrm{~min}$. The effects of the solid-Earth and pole tides were modeled, while ocean loading effects were left unmodeled. The magnitude of the total ocean load in the study region has a maximum of $\sim 30 \mathrm{~mm}$ in the vertical and $\sim 10 \mathrm{~mm}$ in the horizontal components. We modeled the site motion as a random walk, constraining the motion to $1 \mathrm{~mm} \mathrm{~s}^{-1 / 2}$, chosen to maximize the coordinate precisions while not biasing the coordinate estimates. The weighted root mean square of the coordinates of a uniformly moving site suggests that the coordinate precisions are better than $25 \mathrm{~mm}$ in each component. This kinematic approach was adopted after we initially attempted to process the data using a static processing strategy where site coordinates were estimated every 3 hours (Zum- 

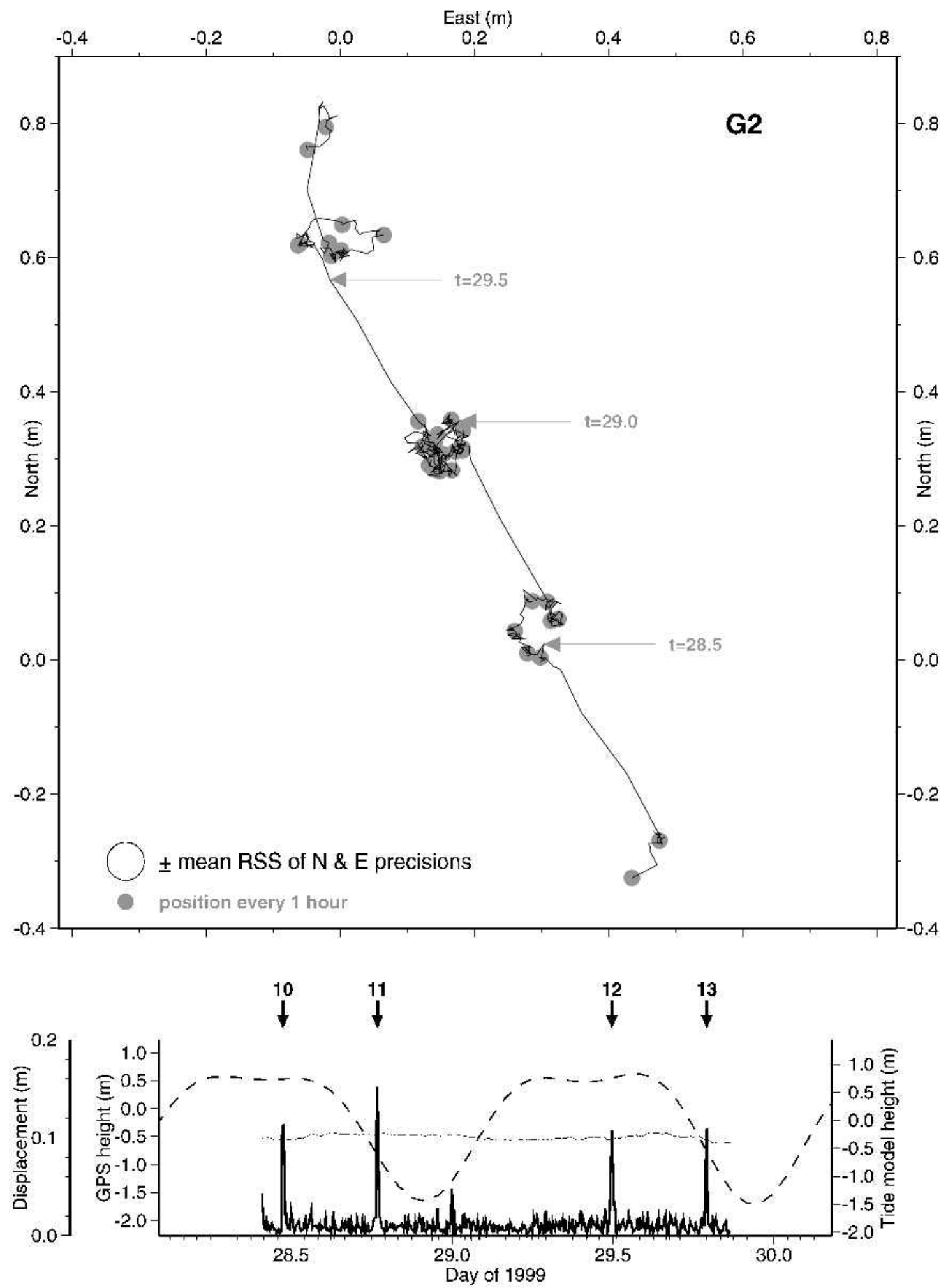

Fig. 3. GPS positions and tidal predictions during second occupation of ice-plain station G2. Upper panel connects station positions every 5 min from processed GPS data with a gray circle every hour and date indicated every 12 hours. Open circle indicates typical mean error of a single GPS position. Lower panel showes vertical position ( thin line), predicted tidal magnitude for a nearby floating position (dashed line) and horizontal displacement (thick line) calculated from 5 min GPS positions. Motion events are indicated by numbered arrows. The spike in displacement at day 29.0 is an artifact of the GPS processing.

berge, 1999). Not only did this static approach lead to results that had a lower temporal resolution compared to those using the kinematic approach, but the horizontal coordinate components also contained spurious signals. This was due to the application of a static processing methodology to data collected at a non-stationary site (King and others, in press).

The GPS data collected in this project are not of suffi- cient duration to accurately extract the tidal contribution to the total vertical displacement signal. We therefore obtain estimates of tidal displacement (and currents) from a numerical tidal model, the Circum-Antarctic Tidal Simulation, version 02.01, CATS02.01 (Padman and others, 2002, in press). CATS02.01 is a high-resolution two-dimensional model of barotropic tides of the Southern Ocean and Ant- 

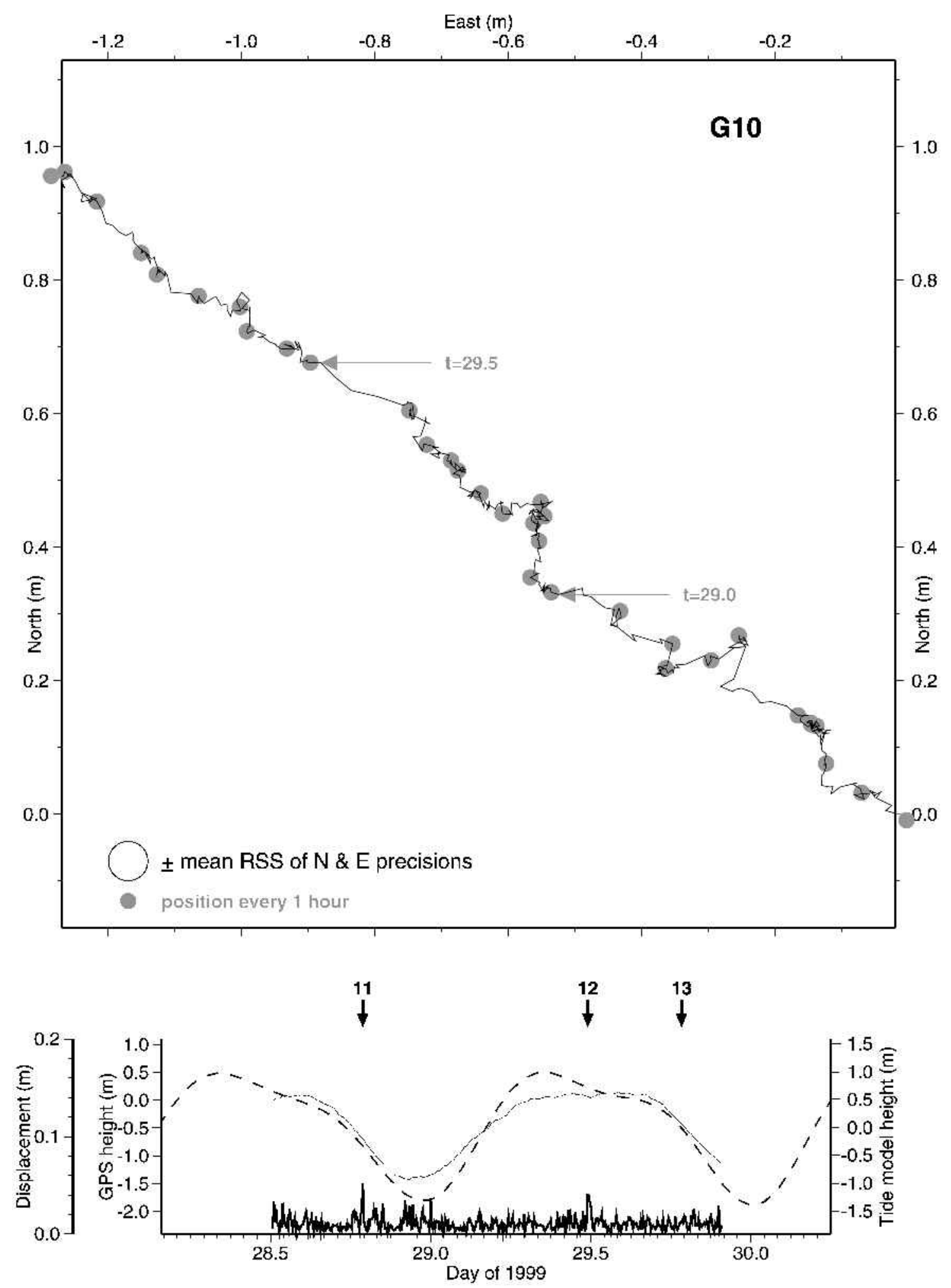

Fig. 4. GPS positions and tidal predictions during second occupation of floating station G10. Legend is identical to Figure 3.

arctic Seas. The model domain extends southward from $58^{\circ} \mathrm{S}$, and explicitly includes the ocean cavities under the Amery, Filchner-Ronne, George VI and Ross Ice Shelves. The resolution is $1 / 4^{\circ}$ east/west and $1 / 12^{\circ}$ north/south, for a typical grid spacing of $\sim 10 \mathrm{~km}$ at $70^{\circ} \mathrm{S}$. The model is forced by height fields along $58^{\circ} \mathrm{S}$ obtained from the Oregon State University TPXO5.1 global tidal solution. Ten constituents are modeled, four diurnal $\left(\mathrm{O}_{1}, \mathrm{~K}_{1}, \mathrm{P}_{1}, \mathrm{Q}_{\mathrm{U}}\right)$, four semi-diurnal $\left(\mathrm{M}_{2}, \mathrm{~S}_{2}, \mathrm{~N}_{2}, \mathrm{~K}_{2}\right)$ and two long-period (month and fortnight) $\left(\mathrm{M}_{\mathrm{m}}, \mathrm{M}_{\mathrm{f}}\right)$. Most of the model details are similar to the model described by Robertson and others (1998), with the exception that CATS02.01 uses linear bottom friction. Output fields are constituent amplitudes and phases for sea surface height and depth-averaged velocity components.

CATS02.01 performs well under the Ross Ice Shelf, as is seen by comparisons with gravimeter records (Williams and Robinson, 1980) and synthetic aperture radar (SAR) interferometry (Padman and others, 2002, in press). Much of the improvement in CATS02.01 compared with earlier models can be attributed to revising the grounding line based on SAR images from RADARSAT (Gray and others, 2002). The choice of linear bottom friction instead of the more usual quadratic formulation also improves the model comparisons with data. 


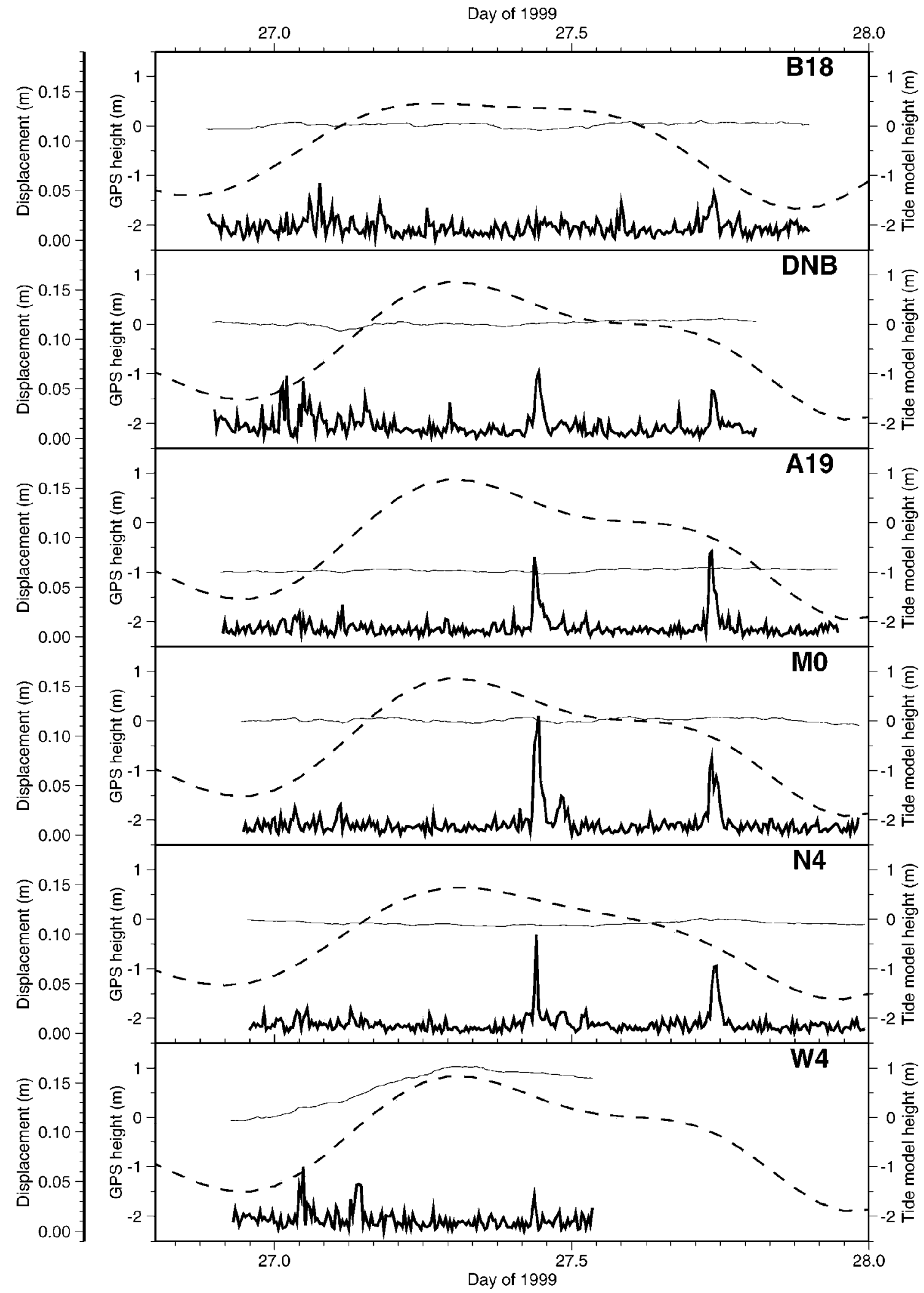

Fig. 5. Concurrent records of displacement at six stations showing the near coincidence of motion events across the study area. Station locations are shown in Figure 1. Dashed lines are predicted tidal magnitudes at nearby floating locations. Thin curves are vertical GPS positions every $5 \mathrm{~min}$. Thick curve is horizontal displacement calculated from GPS positions every $5 \mathrm{~min}$.

\section{DATA ANALYSIS}

Identifying grounded and floating stations

Approximately half of the stations were upstream of the grounding line, and the other half downstream of the grounding line (see Fig. 1). Inspection of the vertical-position time series allowed easy separation of grounded stations (no vertical motion) from floating stations (vertical motion in very good agreement with the predicted tides from CATS02.01). Many of the stations were located close to the grounding line, but there were no stations that showed a "clipped" vertical record suggestive of ephemerally grounded stations, i.e. stations that float at high tide but are grounded at low tide. Six stations (A2, H10, K1, O, G3,W8) are sufficiently close to the expected grounding-line location to assist in 
defining the grounding-line. Based on our observations, stations A2, H10 and $\mathrm{K} 1$ are floating while O, G3 and W8 are grounded. This finding supports the grounding line of Bindschadler (1993), that was based on optical satellite imagery, as the most accurate of the candidate grounding lines published (see Fig. 1).

Comparing the vertical motions at the floating stations (see Fig. 2) with the modeled tidal phase and magnitude shows that the agreement is best for the northernmost stations (BC and J10). Progressing southward from these stations, the observed magnitude becomes an increasingly smaller fraction of the predicted magnitude. At the southernmost station, W4, the observed magnitude is slightly less than half the modeled value. The predicted diurnal tidal phase matches the observation well at all floating stations, with deviations more pronounced for the semi-diurnal tides. The differences between measured and modeled tide heights may arise in two ways. First, there are few water-column thickness data for the long channel south of the Crary Ice Rise, and the tide model solution is sensitive to depth here (the channel is near resonant for semi-diurnal tides; cf. the Bay of Fundy). Second, many of the floating stations are close enough to grounded ice that the elasticity of the ice may impede the ice from experiencing the full range of vertical tidal motion. Ice flexure near the grounding line is not included in the tide model.

\section{Observations of stick-slip motion}

Our data show that horizontal motion throughout most of this region is not steady. Instead, most stations exhibit strongly episodic motion consisting of extended periods with little movement interspersed with large and rapid displacements. Following Fischer and Clarke (1997) who measured similar sudden displacements on Trapridge Glacier, Canada, we refer to this as "stick-slip" motion. This surprising result for the ice stream is best illustrated by the GPScalculated positions during the second occupation of G2 (Fig. 3). Most of the daily motion occurs in two distinct and brief motion events, between which the station is essentially stationary. In some cases, most of the forward motion took place between only two 5 min processing intervals. By comparing the times of these motion events with the predicted tide at the nearest floating location, the first motion event occurred near the end of the high tide, and the second event occurred during the midpoint of the falling tide. This correlation was observed frequently at several stations.

Stick-slip motion events are seen at all stations to varying degrees. Most stations grounded on the ice plain exhibit an extremely low background velocity, with most downstream displacement confined to rapid slip events. Stations on the ice shelf exhibit a higher background velocity than ice-plain stations, but move slower during slip events. Figure 4 shows an example of this behavior from station G10. Station E2.3a, nestled closely against the upstream boundary of the nearly stationary Crary Ice Rise, is perhaps the most firmly grounded station of all, showing the least motion with little evidence of a stick-slip character. A second notable exception for a grounded station is B18, located within $1 \mathrm{~km}$ of the icestream shear margin. Although this station shows numerous motion events, they are considerably less intense and more frequent than at the neighboring station DNB (Fig. 5).
Spatial structure of stick-slip motion

Simultaneous occupations of several GPS stations show that each event is coherent over a broad area. Records for five grounded stations and one floating station during a typical event are given in Figure 5. The sudden jump in displacement is almost ubiquitous, with nearly every event seen at one station also being seen at all other concurrently occupied stations. Figure 2 includes a symbol to indicate when motion events were detected in the GPS data, and vertical lines to show the rough simultaneity of the events. In all, 22 events were identified. Ignoring the nearly stationary station E2.3a, out of 71 opportunities to observe these 22 motion events, events were noted in 61 cases.

Since the GPS data at each site are analyzed using common satellite orbits and clocks, it is important to consider if the source of the events is erroneous GPS results rather than actual ice motions. We are confident that these motions are real, for two reasons. Firstly, the magnitude and the timing of the events vary slightly from site to site. Since satellite position and clock errors would affect each site simultaneously, these cannot be the source of these events. Secondly, the signals are evident only in the horizontal components; there is no evidence of motion in the vertical component. We conclude, therefore, that the GPS coordinate time series precisely represent the actual ice motion. Further confirmation of this conclusion is provided in the correlation between the jumps in the GPS-determined coordinates and independent tidal data as discussed below.

A tidal curve is superimposed on Figure 2 to examine more fully the correlation between slip events and ocean tide. The tidal curve is a composite constructed from individual tide curves that are most representative of the set of GPS stations occupied at any time, and is the most appropriate representation of the tide for the purposes of examining the relationship of recorded slip events to the state of the ocean tide. In some cases, these tidal segments were extended to cover periods of no GPS observations and to make smooth transitions between segments.

Correlation of the events with the tidal record strongly suggests a causal association. The 12 days of field measurements span most of one spring-neap tidal cycle, with neap tide near 23 January and spring tide near 29 January. During spring tides, there is a regular pattern of two motion events per day (see Fig. 2). One event occurs during high tide, and the other midway through the rapidly falling tide. Autocorrelation analysis of the series of events indicates a repeat period of 24.83 hours, very close to the tidal autocorrelation peak of 24.25 hours. This repeat period in tide arises from the superposition of the dominant $\mathrm{K}_{1}$ (period $=23.93$ hours) and $\mathrm{O}_{1}$ (25.82 hours) diurnal constituents that create the spring-neap cycle. The difference between this repeat period and the period of the solar day ( 24.00 hours $)$ is the primary indication that tides rather than radiational forcing are the process causing these events.

Slip events appear to be less regular near neap tide. However, sampling at this time is not sufficient to demonstrate this with certainty, and, in most cases, the same association of slip events with high tide and falling tide still holds. There is one case (event No. 6) that occurs during a rising tide. This may be anomalous, as it occurs immediately after the weakest tide during the entire observation period and there is no monitoring during more than 24 hours preceding this event. 
Table 1. Relative arrival time (in minutes) for numbered events at different stations. Derived velocities for each triplet of stations are presented along the last rows

\begin{tabular}{lccccccccc}
\hline & \multicolumn{10}{c}{ Event No. } & & & \\
& 1 & 2 & 3 & 4 & 8 & 9 & 11 & 12 & 13 \\
& & & & & & & & & \\
\hline A2 & 4 & 8.3 & 0.1 & 6.2 & & & & & \\
G2 & 12.8 & 17.3 & 0.4 & 13.5 & & & 0.3 & 8.3 & 10.3 \\
O & 9 & 14.6 & 0.4 & 8.8 & & & & & \\
W8 & 0 & 0 & 0 & 0 & & & & & \\
A19 & & & & & 1.8 & 0 & & & \\
DNB & & & & & 8.9 & 4.5 & & & \\
M0 & & & & & 8.7 & 1.1 & & & \\
N4 & & & & & 4.8 & 9.9 & & & \\
G3 & & & & & & & 0 & 8.9 & 10.7 \\
H9 & & & & & & & 3.6 & 13.5 & 11.9 \\
Velocity $\left(\mathrm{m} \mathrm{s}^{-1}\right)$ & 83.5, & 53.8, & 1815, & 79.5, & 53.3, & 95.2, & 231.3 & 167 & 613.5 \\
& 17.3 & 1 & 304.7 & 16.5 & 44.2, & 41.5, & & & \\
& & & & & 58.0, & 83.5, & & & \\
& & & & & 115.3 & 48.8 & & & \\
\hline
\end{tabular}

Possible mechanistic explanations for this correlation are discussed in a later section.

\section{Propagation speed of slip motion}

While slip events are seen at multiple stations at about the same time, even with a 5 min parsing of the data we notice that the precise time of a single event at different stations can vary by many minutes. Assuming each event recorded at multiple stations has a single cause, the precise arrival times can be analyzed to locate the source and determine the mean propagation velocity of the event across the region. To estimate the time of maximum displaced motion at better than the 5 min temporal resolution of the GPSderived positions, a parabola was fit to the five displacement measurements nearest each event. The maximum displacement of the fitted parabola was taken as the precise time of the event at that station.

Ice-shelf stations more than a few kilometers from the grounding line had to be excluded from this analysis because arrival delays for floating stations well removed from the grounded ice were very small - often a fraction of a minute. This indicates propagation velocities through the ice shelf very much faster than those calculated for propagation between grounded stations. Given the uncertainties of $1 \mathrm{~min}$ or more in our interpolation of arrival times, the velocities from grounded to floating stations are not reliable; however, they are consistent with the elastic wave velocity in ice of $3830 \mathrm{~m} \mathrm{~s}^{-1}$ (Blankenship and others, 1987).

In principle, four arrival times at four independent sites allow the calculation of the source location as well as propagation velocity. While there were a few opportunities for this calculation, the imprecision of the arrival times made the source location extremely uncertain. Instead, three arrival times were used to calculate the propagation velocity and the direction, but not distance, to the source event by assuming a plane wave and constant velocity. When four stations recorded an event, calculations were completed for each possible station triplet. Table 1 presents the results. The 19 estimates of propagation velocity vary considerably and uncertainties are large. Omitting the two largest velocities produces a mean velocity of $88 \pm 79 \mathrm{~m} \mathrm{~s}^{-1}$. For events $1-4$, the sources were generally southeast of the stations (A2, G2, $\mathrm{O}$ and W8); for events 8 and 9, the sources were south of the stations (A19, DNB, M0 and N4). Both of these directions point toward areas at the south edge of Whillans Ice Stream where comparison of airborne radar soundings indicate ice thickness has increased from mid-1985 to 1999 (R. A. Bindschadler and others, unpublished information). For events 11-13, the sources were located upstream of the stations (G2, G3 and H9), also in a region that airborne radar suggests has thickened.

\section{INTERPRETATION}

Stick-slip motion is a common phenomenon of tectonic processes. Fischer and Clarke (1997) observed stick-slip sliding of Trapridge Glacier and suggested it is caused on that glacier by a relaxation process driven by diurnal fluctuations in surface meltwater production. Surface meltwater is not produced on Whillans Ice Stream, but we hypothesize that fluctuations in the normal pressure, forced by tidal oscillations, may drive a similar relaxation process on the ice plain of Whillans Ice Stream. The process involves the build-up of stored elastic strain in a viscoelastic material, coupled with the sudden elastic release of this strain after failure on a slip plane. The impulsive nature of the events implies some non-linear response to an imposed force. Till samples collected $400 \mathrm{~km}$ upstream on Whillans Ice Stream have been characterized as highly non-linear after laboratory testing (Tulaczyk and others, 2000). In their characterization, water content (expressed as a void ratio) and effective normal stress are the key parameters that determine the failure shear strength of the till. Following Fischer and Clarke (1997), we suggest stored elastic strain may also be important.

The ice plain is a lightly grounded region experiencing very small driving stresses. Ice thicknesses in the region are only a few meters, to a few tens of meters, above flotation (Shabtaie and Bentley, 1987). Subglacial water pressure would reduce the effective normal stresses further. Ice from the upstream portion of Whillans Ice Stream discharges ice into this area and is met by ice from Ice Stream A, creating a modest lateral compression of $24 \mathrm{kPa}$ (Bindschadler and others, 1987), while the Ross Ice Shelf pulls ice from this area under modest tension on the floating ice. Driving stress for the entire region was calculated as $2.6 \mathrm{kPa}$, most of which is balanced by shear stress to the north along the shear margin of Whillans Ice Stream and to the south along the boundary with Ice Stream A and, across A, along the Transantarctic Mountains. The resultant basal shear stress is not significantly different from zero (Bindschadler and others, 1987). Low stresses in this area make it sensitive to even small changes in external forces.

The events we observe correlate with the tidal cycle. Even with no pressurized subglacial water system, the effective pressures on the ice plain are often less than the equivalent of $10 \mathrm{~m}$ of ice. Thus, a $1 \mathrm{~m}$ increase in the tide represents a substantial change to the effective normal stress. By our observations, this tidal magnitude is sufficient to cause regular motion events, whereas the smaller tides seen during the earlier portion of the field period are less able to drive a regular event pacing. Our favored hypothesis is that the tides are forcing changes to the basal condition of the ice plain. Measurements of the surface-horizontal strain rates at many sites on the ice plain show a spatially variable stress 
field that cannot be easily correlated to the surface topography (Bindschadler, 1993). Thus, we conclude that there is spatial heterogeneity in the basal stress field, which is associated with ice overburden pressure on the till. The directions we calculate to event sources point to regions where repeat airborne radar soundings indicate thickening of the ice plain (R.A. Bindschadler, unpublished information). These may be the stickiest spots within the ice plain and control the stick-slip behavior.

Another hypothesis is that the tides change the lateral shear resistance at the shear margin and along the Transantarctic Mountains. The directions to the source locations are consistent with this shear-margin hypothesis but we reject it for two reasons. First, station B18, closest to the shear margin, shows one of the weakest sets of motion events. Second, if the Transantarctic Mountains shear margin was the source of a tidally coupled variation of resistance, we expect the events to occur either at low tide, when the colder upper layers of the ice shelf are in tension and the warmer, lower layers are being compressed, or at mean tide, when lateral compression is minimal. Neither correlation matches our observations.

Any causal mechanism must also explain the falling-tide events. We are less confident of the causes for these events, but suggest that they arise through the influence of lateral stress on the ice base from the sub-shelf tidal current. For our observation period, this current is strongest at falling tide and is directed roughly parallel to the mean ice-flow direction. The ocean tidal currents in this region flow roughly parallel to the peninsula that forms Crary Ice Rise. The predicted spring-tide currents exceed $0.1 \mathrm{~m} \mathrm{~s}^{-1}$ during falling tide, and there may be sufficient sub-shelf roughness caused by bottom crevasses in the area (Jezek and Bentley, 1983), or by smaller-scale features, to transmit sufficient momentum to the basal ice and draw the ice plain forward at the location of the event sources. With nearly negligible basal shear stresses as the mean, even minor increases to the basal shear stress could prove sufficient to trigger falling-tide motion events. They are seen at every falling tide when we have data. During rising tides, ice-shelf basal stress associated with currents flowing against the mean ice-flow direction oppose the driving stresses of the ice-plain system and may help establish the exact timing of the slip events associated with high tide. Thus, the interaction between effective pressure associated with tide height and lateral stresses associated with tidal currents may be significant.

The rapid propagation of events across the ice plain suggests propagation is achieved through an elastic phenomenon. Viscous behavior would tend to dampen the events over even short distances, but they are seen to travel many tens of kilometers. The observations on Ice Stream C by Anandakrishnan and Alley (1997) lend further credence to this concept. At the Upstream B site (400 km from the grounding line), Blankenship and others (1987) reported a compression (P) wave velocity of $1700 \mathrm{~m} \mathrm{~s}^{-1}$ and a shear $(\mathrm{S})$ wave velocity of $150 \mathrm{~m} \mathrm{~s}^{-1}$ in the till and an effective normal stress of $50 \mathrm{kPa}$. Our mean value of propagation velocity is similar to this shear wave velocity, and the normal stresses are likely in the same range. S. Anandakrishnan (personal communication, 2002) suggested our events might be Stokely waves. This type of wave is caused by the shearing motion of one medium against another and travels at about $80 \%$ of the S-wave speed. This possibility was considered by him and Alley in their analysis of the Ice Stream C seismic observations, but rejected because their observed speeds were only $1.6 \mathrm{~m} \mathrm{~s}^{-1}$. The rough agreement of the Stokely wave speed (i.e. $120 \mathrm{~m} \mathrm{~s}^{-1}$ ) with our calculations $\left(88 \pm 79 \mathrm{~m} \mathrm{~s}^{-1}\right)$ is appealing. This explanation also provides a mechanism by which neither compression wave effects nor vertical motion would be produced, while allowing the floating stations to respond to an elastic (compression) wave with propagation speeds faster than our coarse temporal resolution permits us to measure.

We also make the observation that the magnitude of motion displacement is relatively constant for each grounded station. Thus, the displacement for the high-tide event is not three times as large as for the falling-tide event even though the quiescent time for strain to accumulate is roughly three times as long. This suggests that there is some viscous dissipation of the elastic strain, limiting the amount of stored strain for any event. Alternatively, the motion itself may involve deformation of the till, and "dilatancy hardening" could limit the displacement magnitude (Iverson and others, 1998). We favor viscous dissipation because the dilatancy effect would have to be cyclic on the order of minutes to harden and hours to relax. Viscous dissipation may also explain why there were some instances (10 out of 71) where an event was not recorded even though it was expected from the tidal state and the behavior of other stations. Viscous dissipation may be more dominant upstream of the ice plain. At the Upstream B site $400 \mathrm{~km}$ upstream, Harrison and others (1993) observed no diurnal variation in surface velocity, but vertical strain varied diurnally in summer only. Thus, at some distance upstream of the ice plain the inflow of ice must be steady. Our observations show this is yet upstream of the A19/DNB/B18 transect, but, based on the smoother motion of B18 relative to DNB, it may not be far upstream.

We return to the results on Ice Stream D where an inverse correlation between ice speed and tide, i.e. faster flow at low tide, was observed (personal communication from S. Anandakrishnan, 2002). The ice accelerates at falling tide, similar to our observations, but fast motion is sustained at about $50 \%$ above the mean through the entire low-tide period and decelerates at rising tide. This may be similar to the effect we report here if the resistive effect of lateral shear is considered. Our observations are on an iceplain peninsula surrounded by ice shelf and far from laterally resistive mountains or slow-moving ice. The observed region of Ice Stream D is more narrowly confined and shear is expected to form a significant part of the force balance. Thus, in both cases, the bed may be fully lubricated, allowing the ice plain to move very rapidly (up to $15 \mathrm{~km} \mathrm{a}^{-1}$ ) without much resistance while Ice Stream D's shear margins prevent unrestrained motion (up to $0.75 \mathrm{~km} \mathrm{a}^{-1}$ ). Anandakrishnan's data also include the characteristic that the faster motion is not directly downstream but includes a significant lateral component. This may represent the influence of drag imposed by sub-shelf currents, but, because the direction of this current is different underneath $\mathrm{D}$, its influence on the ice-stream motion is different.

\section{GONGLUSIONS}

Stick-slip motion on the ice plain of Whillans Ice Stream is a surprising result. We conclude that the source events are caused by the tides influencing the stress field at the base of the lightly grounded ice plain in two ways. The need for two mechanisms is forced by our observation that, especially during spring tides, there are impulsive motion events at 
high tide and during the falling tide. At high tide, the mechanism we favor is the release of accumulated stress through the reduction of normal stress of the ice on the till. At falling tide, we propose that the sub-shelf tidal currents, which at this phase of the tidal flow are roughly parallel to the mean ice motion, increase the net basal stress sufficiently to release the ever-accumulating stress over the ice plain.

Slip events propagate from one station to another at a mean speed of $88 \pm 79 \mathrm{~m} \mathrm{~s}^{-1}$. This value is intermediate between the rapid elastic wave speed in ice $\left(3830 \mathrm{~m} \mathrm{~s}^{-1}\right)$ and the slower $1.6 \mathrm{~m} \mathrm{~s}^{-1}$ deduced for the till underneath the stagnant Ice Stream C. Our value is close to the shear wave or Stokely-wave velocity and we suggest that these waves trigger the release of stored elastic strain as slip events across the ice plain. The displacement magnitudes are not correlated to the length of the preceding quiescent period, suggesting that some viscous dissipation may occur within the till. Our data did not allow the event-origin sites to be located with confidence, although the calculated directions toward the source events consistently point to regions where the ice plain has thickened since 1985.

The causal mechanics of these events may be similar to those underneath Ice Stream D and represent a characteristic of motion in the mouths of ice streams. On the other hand, we cannot reject the possibility that this peculiar motion is related to the observation of a sustained deceleration of the ice plain and the possible eventual stagnation of Whillans Ice Stream.

\section{AGKNOWLEDGEMENTS}

H. Fricker made perhaps the most important contribution to this paper by suggesting the original three authors speak with M. King on details of GPS processing. The subsequent results markedly altered and improved this research. Also, discussions with M. A. Fahnestock, S. Anandakrishnan, U. Fischer, C. S. M. Doake and R. B. Alley led to improved insights and analysis. Excellent reviews were provided by $\mathrm{T}$. Hughes and J. Kavanaugh. The work was supported by U.S. National Science Foundation (NSF) grant OPP-9616394 to R.B., and NASA (NAG5-7790) and the NSF Office of Polar Programs (OPP-9896006) to L.P.

\section{REFERENGES}

Alley, R. B., D. D. Blankenship, S. T. Rooney and C. R. Bentley. 1989. Sedimentation beneath ice shelves - the view from Ice Stream B. Mar. Geol., 85 $(2 / 4), 101-120$.

Anandakrishnan, S. and R. B. Alley. 1997. Tidal forcing of basal seismicity of Ice Stream C, West Antarctica, observed far inland. 7. Geophys. Res., 102(B7), 15,183-15,196.

Anandakrishnan, S., D. E. Voigt, R. B. Alley and M. A. King. 2003. Ice Stream D flow speed is strongly modulated by the tide beneath the Ross Ice Shelf. Geophys. Res. Lett., 30(7). (10.1029/2002GL016329.)

Bindschadler, R. 1993. Siple Coast Project research of Crary Ice Rise and the mouths of Ice Streams B and C, West Antarctica: review and new perspectives. 7. Glaciol., 39(133), 538-552.

Bindschadler, R. and P. Vornberger. 1998. Changes in the West Antarctic ice sheet since 1963 from declassified satellite photography. Science, 279(5351), 689-692.

Bindschadler, R. A., S. N. Stephenson, D. R. MacAyeal and S. Shabtaie. 1987. Ice dynamics at the mouth of Ice Stream B, Antarctica. F. Geophys. Res., 92(B9), 8885-8894.

Blankenship, D. D., C. R. Bentley, S. T. Rooney and R. B. Alley. 1987. Till beneath Ice Stream B. 1. Properties derived from seismic travel times. 7. Geophys. Res., 92(B9), 8903-8911.

Doake, C.S.M. and 6 others. 2002. Tidal movement of Brunt Ice Shelf, Antarctica. Geophys. Res. Lett., 29(8). (10.1029/2001GL014606.)

Engelhardt, H. and B. Kamb. 1997. Basal hydraulic system of a West Antarctic ice stream: constraints from borehole observations. F. Glaciol., 43(144), 207-230.

Engelhardt, H. and B. Kamb. 1998. Basal sliding of Ice Stream B, West Antarctica. 7. Glaciol., 44(147), 223-230.

Fischer, U. H. and G. K. C. Clarke. 1997. Stick-slip sliding behaviour at the base of a glacier. Ann. Glaciol., 24, 390-396.

Gray, L. and 6 others. 2002. RADARSAT interferometry for Antarctic grounding-zone mapping. Ann. Glaciol., 34, 269-276.

Harrison, W. D., K. A. Echelmeyer and H. Engelhardt. 1993. Short-period observations of speed, strain and seismicity on Ice Stream B, Antarctica. 7. Glaciol., 39(133), 463-470.

Iversen, N. R., T. S. Hooyer and R. W. Baker. 1998. Ring-shear studies of till deformation: Coulomb-plastic behavior and distributed strain in glacier beds. F. Glaciol., 44(148), 634-642.

Jezek, K. C. and C. R. Bentley. 1983. Field studies of bottom crevasses in the Ross Ice Shelf, Antarctica. 7. Glaciol., 29(101), 118-126.

Joughin, I. and S. Tulaczyk. 2002. Positive mass balance of the Ross Ice Streams, West Antarctica. Science, 295(5554), 476-480.

Kamb, B. 2001. Basal zone of the West Antarctic ice streams and its role in lubrication of their rapid motion. In Alley, R. B. and R. A. Bindschadler, eds. The West Antarctic ice sheet: behavior and environment. Washington, DC, American Geophysical Union, 157-199. (Antarctic Research Series 77.)

King, M. A., R. Coleman and L. Nguyen. In press. Spurious periodic horizontal signals in sub-daily GPS posiiton estimates. F. Geod.

Meier, M. F. and A. Post. 1987. Fast tidewater glaciers. F. Geophys. Res., 92(B9), 9051-9058.

O'Neel, S., K. A. Echelmeyer and R.J. Motyka. 2001. Short-term flow dynamics of a retreating tidewater glacier: LeConte Glacier, Alaska, U.S.A. F. Glaciol., 47(159), 567-578.

Padman, L., H. A. Fricker, R. Coleman, S. Howard and L. Erofeeva. 2002 A new tide model for the Antarctic ice shelves and seas. Ann. Glaciol., 34, 247-254.

Padman, L., S. Erofeeva and I. Joughin. In press. Tides of the Ross Sea and Ross Ice Shelf. Antarct. Sci.

Shabtaie, S. and C. R. Bentley. 1987. West Antarctic ice streams draining into the Ross Ice Shelf: configuration and mass balance. F. Geophys. Res., 92(B2), 1311-1336. (Erratum: 92(B9), 1987, p. 9451.)

Tulaczyk, S. M., B. Kamb and H. F. Engelhardt. 2000. Basal mechanics of Ice Stream B, West Antarctica. I. Till mechanics. F. Geophys. Res., 105(B1), 463-481.

Walters, R. A., and W. W. Dunlap. 1987. Analysis of time series of glacier speed: Columbia Glacier, Alaska. 7. Geophys. Res. 92(B9), 8969-8975

Whillans, I. M. and C. J. van der Veen. 1997. The role of lateral drag in the dynamics of Ice Stream B, Antarctica. F. Glaciol., 43(144), 231-237.

Whillans, I. M., C. R. Bentley and C. J. van der Veen. 2001. Ice Streams B and C. In Alley, R. B. and R. A. Bindschadler, eds. The West Antarctic ice sheet: behavior and environment. Washington, DC, American Geophysical Union, 257-281. (Antarctic Research Series 77.)

Williams, R.T. and E. S. Robinson. 1980. The ocean tide in the southern Ross Sea. 7. Geophys. Res., 85(C11), 6689-6696.

Zumberge, J. F. 1999. Automated GPS data analysis service. GPS Solutions, 2(3), 76-78.

Zumberge, J. F., M. B. Heflin, D. C. Jefferson, M. M. Watkins and F. H. Webb. 1997. Precise point positioning for the efficient and robust analysis of GPS data from large networks. f. Geophys. Res., 102(B3), 5005-5017. 